\title{
Origem, Evolução e Estado Atual dos Serviços de Documentação no Brasil
}

\author{
Edson Nery da Fonseca \\ Professor universitário (UnB)
}

SUMÁRIO: 1 - Documentação em sentido amplo. 2 - Documentação em sentido restrito. 3 - Precursores brasileiros. 4 - Primeiro serviço de documentação. 5 - Outras iniciativas governamentais. $6-$ Iniciativas individuais. 7 - Instituto Brasileiro de Bibliografia e Documentação. 8 - Depois do IBBD. 9 - Problemas atuais.

\section{1 - DOCUMENTAÇÃO EM SENTIDO AMPLO}

Com a autoridade indiscutivel de quem exerceu, durante mais de uma década, o alto cargo de Ministro da Educação e Cultura, o Senador Gustavo Capanema observou certa vez que "um dos grandes defeitos da nossa cultura consiste na falta ou insuficiência de documentação".

A observação foi feita durante a 12." reunião da comissão que' elaborou o projeto da Constituição Brasileira de 1946, tendo sido suscitada por uma estranha sugestão do Sr. Guaraci Silveira: a de que os debates deixassem de ser taquigrafados, para que os constituintes pudessem falar com mais naturalidade.

Manifestaram-se contrários, além do Sr. Guistavo Capanema, os também deputados Artur Bernardes e Aliomar Baleeiro e o senador Ivo d'Aquino. Mas o fato é que a estapafúrdica idéia se transformou em proposta do deputado Soares Filho, aprovada pela chamada Grande Comissão da Assembléia Constituinte de 1946. ${ }^{1}$ 
Este é apenas um dos inúmeros exemplos de desapreço pela documentação no Brasil. Outro exemplo é o deplorável estado em que se encontra a maior parte dos nossos arquivos públicos e privados, onde apodrecem e de onde desaparecem - com uma exceção ou outra, como, por exemplo, as do Arquivo Nacional e dos Estaduais de Pernambuco, da Bahia e de São Paulo - documentos importantíssimos. Sobre este particular, convém ler o livro de Franklin de Oliveira, significativamente intitulado Morte da memória nacional. ${ }^{2}$

Em crônica publicada no ano de 1958, Carlos Drummond de Andrade referiu-se ao "sentimento nacional da inutilidade do papel velho" e também ao "desamor à documentação, a pobreza de consciência histórica, a falta de senso arquivístico, que fazem com que os acervos cartoriais entre nós sejam não raro tão maltratados". Observou ainda o poeta-cronista que "no serviço público, chama-se "arquivo morto" justamente àquele núcleo de papéis em que a história começa a viver, e que portanto merece especiais cuidados". O próprio Drummond de Andrade informa qual o destino desses papéis: "joga-se fora, queima-se, vende-se a quilo, porque temos horror ao passado e o futuro não nos interessa". ${ }^{3}$

O exemplo máximo de desprezo pela documentação no Brasil é a queima dos arquivos da escravidão, ordenada por despacho de Rui Barbosa, quando Ministro da Fazenda, em 14 de dezembro de 1890. Alega-se em favor do grande brasileiro que, mandando queimar os livros de matrícula geral dos escravos do Império, ele evitou as vultosas despesas de indenização que os escravocratas certamente pretenderiam, com base naqueles documentos; argumenta-se também que o seu gesto exprimiu um sentimento nacional, tanto que foi muito aplaudido pelos abolicionistas. Não nos compete apreciar o mérito da iniciativa que, justificável ou não, permanece como exemplo gritante de desprezo pela documentação. A defesa de Rui Barbosa foi feita pelo historiador Américo Jacobina Lacombe, ${ }^{4}$ mas existem vários outros casos de documentos destruídos e desaparecidos, como assinala o professor José Honório Rodrigues. ${ }^{5}$

\section{2 - DOCUMENTAÇÃO EM SENTIDO RESTRITO}

Falou-se, até aqui, de documentação no sentido mais amplo, que compreende a reunião ou coleção de documentos de qualquer natureza, devidamente conservados e organizados paR. Serv. Públ., Brasilia, 108 (1): jan/abr. 1973 
ra fins de consulta, estudo ou prova. A acepção técnica é mais restrita, indicando as operações de análise do conteúdo dos documentos escritos ou textuais - livros, artigos, relatórios, teses, etc. - com o objetivo de preparar resumos e índices temáticos.

$\mathrm{Na}$ análise documental empregou-se, inicialmente, o sistema de Classificação Decimal Universal (CDU), desenvolvido pelos belgas Paul Otlet (1868-1944) e Henri La Fontaine (1854-1943) a partir da Classificação Decimal do norte-americano Melvil Dewey (1851-1931), concebida para ordenação de livros e periódicos em bibliotecas.

Assim, desde suas origens, a documentação distinguiu-se claramente da biblioteconomia, embora fosse evidente sua ligação com a bibliografia, da qual se desprenderia quando a CDU começou a ser aplicada em arquivos e outros órgãos documentológicos. ${ }^{6}$

Quem melhor esclareceu a distinção entre bibliografia e documentação foi a Sra. Louise-Noëlle Malclès, ao escrever que esta "não é mais do que a bibliografia ultrapassada no seu conteúdo e acelerada na sua marcha". ${ }^{7}$ Ultrapassada no seu conteúdo porque passou a resumir documentos gráficos de qualquer natureza, em vez de apenas referenciar livros; acelerada na sua marcha porque procurou "marchar com os fatos", em vez de seguir atrás deles, como a bibliografia tradicional. ${ }^{8}$

Dispenso-me de repetir aqui a história do Escritório Internacional de Bibliografia que Otlet e La Fontaine fundaram em Bruxelas, no ano de 1892 , e no qual começaram a organizar, de acordo com a CDU, um catálogo mundial em fichas; e a da criação do Instituto Internacional de Bibliografia (IIB) em 1895, pelos que tiveram o ensejo de ver esse catálogo, na primeira Conferência Internacional de Bibliografia. É uma história já conhecida pelo depoimento de uma testemunha ocular: o inglês S.C. Bradford. ${ }^{9}$

\section{3 - PRECURSORES BRASILEIROS}

Apesar das incompreensões e despeitos que enfrentou tanto da parte dos norte-americanos da Smithsonian Institution como dos ingleses da Royal Society - o IIB logrou despertar grandes entusiasmos entre os primeiros documentalistas do 
mundo: os que faziam documentação como Mr. Jourdain fazia prosa e para os quais a CDU era uma espécie de deus ex machina. Como observa a Sra. Kathrine O. Murra, "a conquista de adeptos cedo transformou-se numa cruzada". ${ }^{10} \mathrm{E}$ entre os primeiros apóstolos da CDU estavam três brasileiros: os sábios Juliano Moreira e Oswaldo Cruz e o engenheiro civil Vítor Alves da Silva Freire.

Quatro anos depois de fundado em Bruxelas, o IIB contava com um membro brasileiro - Juliano Moreira - que utilizou a CDU na revista por ele dirigida: os Annaes da Sociedade de Medicina e Cirurgia da Bahia. ${ }^{11}$ Em 1900, outro grande cientista brasileiro introduzia o sistema na biblioteca do instituto que organizara e teve depois o seu nome: o Instituto Oswaldo Cruz. ${ }^{12} \mathrm{Em}$ dezembro do mesmo ano, o engenheiro paulista Vitor Alves da Silva Freire - diplomado pela Escola Politécnica de Paris, Diretor de Obras Municipais e lente substituto da Escola Politécnica de São Paulo - publicava em revista da mesma Escola um artigo sobre a necessidade da participação do Brasil na organização internacional da bibliografia científica. ${ }^{13}$

O opúsculo de Vítor Alves da Silva. Freire foi o primeiro trabalho em lingua portuguesa a receber o número de publicação oficial do IIB, transformado em Instituto Internacional de Documentação no ano de 1931 e em Federação Internacional de Documentação (FID) em 1938. Vê-se pelo seu texto que já no começo do século havia em São Paulo uma casa comercial - a Livraria Civilização, de Mello, Barjona \& Cia., estabelecida à Rua Quinze de Novembro, $n .^{\circ} 58$ - recebendo assinaturas e encomendas de publicações do IIB e fornecendo equipamentos e móveis internacionalmente padronizados.

A Biblioteca da Câmara dos Deputados também está entre as primeiras do País que adotaram o catálogo sistemático segundo a CDU e receberam as publicações do IIB, graças à clarividência do seu diretor, que era, na época, o escritor Mário de Alencar (1872-1925), filho de José de Alencar e amigo íntimo de Machado de Assis.

\section{4 - PRIMEIRO SERVIÇO DE DOCUMENTAÇÃO}

Nenhum brasileiro, porém, entusiasmou-se mais com a CDU e com os trabalhos do IIB do que o jurista e homem público Manuel Cícero Peregrino da Silva (1866-1956). Diretor da Biblio- 
teca Nacional de 1900 a 1921 - com interrupção de 1916 a 1918 para exercer os altos cargos de Diretor-Geral da Instrução Pública e Prefeito interino do Distrito Federal — os pontos mais altos de sua brilhante administração foram a reorganização geral da repartição, a construção do edifício atual, a criação do primeiro curso de biblioteconomia da América Latina e a fundação de um Serviço de Bibliografia e Documentação em correspondência com o IIB.

É lamentável que os sucessores imediatos de Manuel Cícero Peregrino da Silva na direção da Biblioteca Nacional não se tenham interessado por esse Serviço de Bibliografia e Documentação, no qual foram previstas quase todas as peças dos modernos centros de documentação. A ele caberia, entre outras atribuições, "a organização, segundo o sistema de Classificação Decimal e por meio de fichas, do' repertório bibliográfico brasileiro, como contribuição para o repertório bibliográfico internacional (.), incluídos os artigos insertos em publicações periódicas e os escritos de qualquer natureza", a impressão de fichas catalográficas, a "organização do catálogo coletivo das bibliotecas brasileiras" e concursos destinados a premiar, de dois em dois anos, os melhores trabalhos bibliográficos publicados no país. Quando examinarmos, no item 7 deste artigo, o Instituto Brasileiro de Bibliografia e Documentação, veremos que nele se concretizou o sonho e o plano desse Otlet brasileiro que foi o pernambucano Manuel Cícero Peregrino da Silva. ${ }^{14}$

O Boletim Bibliographico da Bibliotheca Nacional do Rio de Janeiro dos anos de 1918 a 1921 é o que resta do Serviço de Bibliografia e Documentação criado por iniciativa de Manuel Cícero Peregrino da Silva: uma publicação da qual podemos dizer - repetindo o julgamento de Fidelino de Figueiredo sobre - Catalogo da Exposição de Historia do Brasil - que honra a biblioteconomia brasileira da época. Organizado por Cícero de Brito Galvão, ele tem arranjo sistemático de acordo com a CDU e de cada número existem duas edições, sendo uma impressa de um só lado, para que as referências bibliográficas pudessem ser recortadas e montadas nas fichas do Repertório Bibliográfico Universal. 15

A primeira guerra mundial foi, como se sabe, uma das causas do fracasso da experiência tentada por Otiet e La Fontaine para o estabelecimento do primeiro catálogo coletivo de 
que se tem notícia no mundo. Mas outros centros nacionais de documentação - como o Nederlands Instituut voor Documentatie en Registratuur (NIDER) e a British Society for International Bibliography - continuaram colaborando com o IIB - que passou a ser uma entidade menos executora do que coordenadora de atividades documentológicas - enquanto no Brasil se interrompia a iniciativa pioneira de Manuel Cícero Peregrino da Silva.

\section{5 - OUTRAS INICIATIVAS GOVERNAMENTAIS}

Não houve um serviço de Documentação, dentre os criados entre nós a partir de 1937, que procurasse reatar aquela iniciativa. A Biblioteca Nacional voltou a aquietar-se em medíocre repartição pública, deixando de ser a instituição dinamicamente cultural que foi durante as administrações de Benjamin Franklin Ramiz Galvão e Manuel Cícero Peregrino da Silva. Parecia, como observou ironicamente Gilberto Freyre, "que estava se desencarnando em fantasma: um fantasma do Rio de Janeiro dos dias do Engenheiro Passos e do Engenheiro Sousa Aguiar". 16

Enquanto isso, o governo instaurado em 10 de novembro de 1937 transformava os velhos Serviços de Publicidade em Serviços de Documentação. Foi o que aconteceu com o do Departamento Administrativo do Serviço Público, ${ }^{17} \mathrm{com}$ o do então chamado Ministério da Educação e Saúde ${ }^{18}$ e com o do Ministério da Agricultura. 19 Serviços de Documentação foram criados, em seguida, nos Ministérios que não dispunham de Serviços de Publicidade, como o das Relações Exteriores, 20 o da Marinha, ${ }^{21}$ o da Justiça e Negócios Interiores, ${ }^{22}$ o da Viação e Obras Públicas ${ }^{23}$ e 0 do Trabalho, Indústria e Comércio. ${ }^{24}$

Alguns desses serviços limitavam-se a publicar livros e revistas de propaganda governamental: uma propaganda da qual podemos dizer, parafraseando François Porché, "que não ousava dizer o seu nome". É de justiça mencionar, entretanto, o Ministério da Justiça e Negócios Interiores - pioneiro da documentação legislativa no Brasil, através da revista Jus Documentação ${ }^{25}$ - o Ministério da Educação e Cultura - cujo Serviço de Documentação, ao tempo em que foi dirigido pelo professor José Simeão Leal, editou publicações avulsas, seriadas e períodicas do mais alto nivel cultural e gráfico ${ }^{26}-\mathrm{e} 0$ Ministério da Agricultura, que preferiu, em vez da falsa doR. Serv. Públ., Brasilia, 108 (1): jan/abr. 1973 
cumentação, a informação agrícola, tão necessária a um País como o Brasil. ${ }^{27}$

O Serviço de Documentação do DASP não fez - nem tinha este objetivo - documentação no sentido técnico da palavra, mas procurou debater o problema em cursos especializados e em editoriais e artigos da Revista do Serviço Público. ${ }^{28}$ Basta lembrar que o único trabalho de Paul Otlet até agora traduzido em português foi publicado nesta revista. Refiro-me ao notável ensaio que é "Documentos e Documentação". ${ }^{29}$

\section{6 - INICIATIVAS INDIVIDUAIS}

A análise de publicações periódicas (dépouillement) para extração de informações divulgadas em resumos e indices é, como assinala a Sra. Louise-Noëlle Malclès, uma operação estreitamente ligada ao conceito moderno de documentação. ${ }^{30}$ Enquanto os serviços de documentação governamentais, com as exceções indicadas, se resignavam às melancólicas tarefas de endeusamento de autoridades e divulgação da sub-literatura dos áulicos, alguns abnegados procuravam fazer o dépouillement de periódicos especializados, divulgando índices que podem ser considerados como os primeiros instrumentos documentográficos brasileiros.

O precursor foi o médico paulista Jorge de Andrade Maia (1892-1960), bibliotecário-chiefe da Faculdade de Medicina da Universidade de São Paulo, de 1927 até o ano de sua morte. Além de indexar revistas paulistas de ciências biomédicas e de bibliografar as teses defendidas perante a Faculdade de Medicina da Universidade de São Paulo, Jorge de Andrade Maia publicou o índice-Catálogo Médico Paulista (1860-1936) e o Índice-Catálogo Médico Brasileiro (1937-1958), esta continuada pelo Instituto Brasileiro de Bibliografia e Documentação com o título de Bibliografia Brasileira de Medicina. ${ }^{31}$

Não é por acaso que esses primeiros dépouillements brasileiros são especializados em ciências biomédicas. Sendo essas ciências de importância fundamental para a saúde pública, nelas é que a documentação primeiro se apresentou, no Brasil e no mundo, como condição sine qua non de uma terapêutica atualizada. Vale recordar, embora de passagem, que o autor das primeiras bibliografias do mundo, elaboradas ainda na era dos manuscritos, foi o famoso Galeno; e que os funda- 
dores da bibliografia nacional foram os médicos Benjamin Franklin Ramiz Galvão e Augusto Vitorino Alves Sacramento Blake. ${ }^{32}$

Há que destacar, ainda que em setor especializadíssimo das ciências biomédicas, o trabalho notável da bibliotecária paulista Luiza Keffer no Departamento de Profilaxia da Lepra, de São Paulo. ${ }^{33}$

Também precursoras no dépouillement de periódicos especializados são as bibliotecárias Dolores Iglésias e Maria de Lourdes Meneghezzi, com a monumental Bibliografia e Índice da Geologia do Brasil. Ao primeiro volume, que referencia quase trezentos anos de literatura de geo-ciências sobre o Brasil, seguiram-se outros igualmente publicados pelo Departamento $\mathrm{Na}$ cional da Produção Mineral. ${ }^{34}$

\section{7 - INSTITUTO BRASILEIRO DE BIBLIOGRAFIA E DOCUMENTAÇÃO}

Até 1954 - que pode ser considerado, como veremos, um ano-chave para a documentação em nosso País - o dépouillement de periódicos permaneceu, como já vimos, limitado ao esforço individual de alguns bibliotecários já conscientes que o progresso da ciência - tanto quanto o das letras e das artes - exige algo mais do que a classificação e a catalogação de livros no tranqüilo ambiente das bibliotecas: aquele "repouso de centro do mundo" de que fala o poeta E. Carréra Guerra.

A criação, naquele ano, do Instituto Brasileiro de Bibliografia e Documentação (IBBD) foi um passo decisivo para coordenação e estímulo dessas iniciativas individuais, representando verdadeiro desabrochar da semente lançada por Manuel Cícero Peregrino da Silva, como salientou a Sra. Lydia de Queiroz Sambaquy. ${ }^{35}$

Criada para promover o desenvolvimento da educação, da ciência e da cultura, a Unesco procurou sempre estimular a fundação de centros de bibliografia e documentação nos paises membros. Conhecendo o interesse da Fundação Getúlio Vargás pelo assunto - interesse manifestado no estabelecimento do primeiro catálogo coletivo nacional, na manutenção de um serviço de reprografia e na publicação da Bibliografia EconômicoSocial ${ }^{36}$ - sugeriu-Ihe a referida organização das Nações Unidas que iniciasse diligências para a instalação, no Brasil, de um centro bibliográfico nacional. 
Duas bibliotecárias da Fundação Getúlio Vargas - as Sras. Lydia de Queiroz Sambaquy e Jannice de Mello Monte Mor - foram escolhidas para visitar, sob os auspícios da Unesco, os principais serviços dessa natureza na Europa e nos Estados Unidos. Ao mesmo tempo, a Unesco enviou ao Brasil, como consultor do projeto, o engenheiro químico Herbert Coblans, especializado em documentação científica.

Dois órgãos governamentais - o Conselho Nacional de Pesquisas e o Departamento Administrativo do Serviço Público - também se interessaram pelo projeto e participaram dos estudos preliminares que resultaram na fundação, em 1954, do Instituto Brasileiro de Bibliografia e Documentação. O IBBD foi incluído na estrutura do Conselho Nacional de Pesquisas, de acordo com a lei que criou este órgão da Presidência da República. ${ }^{37}$

A presença do doutor Herbert Coblans no Brasil, durante os estudos sobre a criação do IBBD, foi importantíssima para a conscientização do problema da documentação, tanto entre bibliotecários como nos meios científicos, onde era fraternalmente acolhido. Seu artigo "Técnica de documentação na organização da literatura científica" foi talvez o primeiro trabalho sobre documentação, publicado em revista científica brasileira. Nele o doutor Coblans demonstrou, em síntese magistral, a situação da informação científica no mundo, salientando as responsabilidades que cabem a bibliotecários e pesquisadores. ${ }^{38}$

Em dez conferências proferidas na Biblioteca Nacional, a convite do seu Diretor-Geral Eugênio Gomes, o doutor Herbert Coblans desenvolveu as informações e conceitos do artigo publicado em Ciência e Cultura. Este foi o primeiro curso sobre documentação promovido no Brasil com abordagem de problemas da informação científica, em vez das fastidiosas dissertações sobre bibliotecas, arquivos e museus que caracterizaram cursos anteriores com a mesma denominação. As conferências do professor Herbert Coblans foram ampliadas e publicadas no livro Introdução ao estudo de documentação, publicados pelo DASP. 39

Incorporando órgãos já existentes - como o Serviço de Intercâmbio de Catalogação, da Biblioteca do DASP e o Catálogo Coletivo iniciado pela Fundação Getúlio Vargas - o IBBD formou a melhor biblioteca brasileira especializada em docu- 
mentação, bibliografia e biblioteconomia, montou um bem equipado laboratório reprográfico e criou serviços de informações técnico-científicas, de bibliografia e de publicações que não tardaram em oferecer aos pesquisadores brasileiros os documentos estrangeiros de que necessitavam, bem como a todos os interessados, no Brasil e no mundo, referências bibliográficas dos trabalhos realizados pelos nossos próprios cientistas.

Paralelamente, outras iniciativas, foram ampliando o campo de ação do IBBD, como cursos de aperfeiçoamento que trouxeram ao Brasil especialistas estrangeiros da categoria de Jesse H. Shera (1957) e Jacques Samain (1958), acordos com universidades para formação de catálogos coletivos regionais, filiação à Federação Internacional de Documentação - da qual tornou-se membro nacional - articulação com os trabalhos da Organização Internacional de Normalização (ISO), através da Associação Brasileira de Normas Técnicas (ABNT), publicação de edições em lingua portuguesa do sistema CDU, em colaboração com o Instituto de Alta Cultura de Portugal, etc.

\section{8 - DEPOIS DO IBBD}

O primeiro fruto da criação do IBBD foi o generalizado interesse pela documentação em todo o País, a julgar pela publicação de artigos em revistas culturais ${ }^{40}$ e sobretudo na Revista do Serviço Público; ${ }^{41}$ pela realização, em 1956, de um Simpósio sobre Bibliografia e Documentação Científica, promovido em São Paulo pela Sociedade Brasileira para o Progresso da Ciência; ${ }^{42}$ por cursos especializados em Fortaleza, no Recife, no Rio de Janeiro e em outras capitais; e até por uma página inteira do Suplemento Dominical de um jornal do Rio de Janeiro, dedicada à documentação. ${ }^{43}$ Debates sobre documentação têm sido promovidos, desde então nas reuniões anuais da Sociedade Brasileira para o Progresso da Ciência. Os Congressos Brasileiros de Biblioteconomia - iniciados no Recife, em 1954 - passaram a intitular-se, a partir do segundo - realizado na cidade de Salvador, em 1959 - Congressos Brasileiros de Biblioteconomia e Documentação. No currículo mínimo aprovado, em 1962, pelo Conselho Federal de Educação, aparece pela primeira vez a matéria Documentação, desdobrada por alguns cursos em várias disciplinas obrigatórias e opta-
tivas. ${ }^{44}$ 
Outro nome deve ser associado ao desenvolvimento da informação científica - expressão que, segundo alguns autores, substitui a palavra documentação - em nosso País: o do médico e documentalista português Zeferino Ferreira Paulo. Com seu extraordinário dinamismo, percorreu ele todo o Brasil, proferindo palestras, dirigindo cursos e estimulando atividades documentológicas em todos os setores.

Sob tais influxos, vários serviços de documentação foram criados ou simplesmente projetados. Restringindo-se o presente artigo aos órgãos efetivamente instalados, remetemos os interessados pelos projetos às publicações que os descrevem ou referenciam, como, por exemplo, a revista Ciência da Informação ${ }^{45}$ e a Bibliografia Brasileira de Documentação. ${ }^{46}$

Dentre os serviços especializados, devem ser mencionados 0 da empresa Petróleo Brasileiro S/A (PETROBRAS), ${ }^{47}$ os do Grupo Coordenador do Desenvolvimento da Pesca e da Divisão de Coordenação do Plano Diretor, ambos da Superintendência do Desenvolvimento do Nordeste (SUDENE), ${ }^{48}$ o do Conselho Nacional de Estatística - hoje Instituto Nacional de Estatística da Fundação IBGE ${ }^{49}$ - e o do Centro Brasileiro de Pesquisas Educacionais. ${ }^{50}$ Esta, entretanto, é uma relação menos exaustiva do que exemplificativa.

\section{9 - PROBLEMAS ATUAIS}

Com a criação de novos Ministérios e a execução da Reforma Administrativa, outros serviços de documentação governamentais foram criados, sendo os antigos reestruturados. Alguns desses Serviços transformaram-se em Divisões - como no Ministério da Fazenda - enquanto outros - como os do DASP, Ministério do Trabalho e Previdência Social e Ministério dos Transportes - adotaram um título mais atual: Centros de Documentação e Informática.

A criação e reestruturação desses serviços, divisões e centros deveriam obedecer a um planejamento global, de acordo com as próprias diretrizes governamentais. Se a coordenação já era uma necessidade na época dos processos manuais e mecânicos, muito mais imperiosa se faz sentir atualmente, em face dos custosos equipamentos de processamento eletrônico da informmação: equipamentos exigidos pela explosão bibliográfica. 
Esta é a lição que nos chega de países desenvolvidos ${ }^{51}$ e a recomendação de especialistas convocados pela Unesco para elaboração de um sistema internacional de informação científica. Como demonstram esses especialistas, as redes (networks) converteram-se rapidamente numa preocupação constante das autoridades governamentais, em níveis nacional e regional. ${ }^{52}$

O que infelizmente se verifica no Brasil é uma desenfreada competição de serviços governamentais independentes: competição que ocorre tanto na área do Poder Executivo como nas do Legislativo e do Judiciário. Parece até que, na estrutura constitucional do País, se procura corrigir o velho Montesquieu, instituindo-se quatro Poderes em vez de três.

Não exageramos ou fazemos blague e nem seria lícito admitir exagero ou ironia em matéria de tal magnitude. O Senado Federal e a Câmara dos Deputados têm competência constitucional para organizarem seus serviços administrativos (Art. 30 da Constituição). Mas, como recentemente o fizeram, parecem menos duas Câmaras que dois Poderes, independentes e desarmônicos entre si. Porque na Resolução n. ${ }^{\circ}$ 58, de 1972 , do Senado Federal, aparecem vários serviços de documentação bibliográfica, arquivística, legislativa - já existentes ou previstos pela Resolução $n .^{\circ} 20$, de 1971, da Câmara dos Deputados. Os textos estão publicados para a indispensável comparação. ${ }^{53}$ Eles mostram que o Congresso Nacional - expressão constitucional do Poder Legislativo - só funciona harmonicamente durante efêmeras sessões conjuntas.

\section{REFERENCIAS BIBLIOGRÁFICAS}

1 - BRASIL. Assembléia Constituinte, 1946. Anais da Comissão da Constituição, organizados pela Redação de Anais e Documentos Parlamentares. Rio de Janeiro, Imprensa Nacional, 1948, v. I, p. 318.

2 - OLIVEIRA, Franklin de. Morte da Memória Nacional. Rio de Janeiro, Civilização Brasileira, 1967. 236 p.

3 - ANDRADE, Carlos Drummond de. Papel velho. Correio da Manhã (Rio de Janeiro) 3 de agosto de $1958,10^{\circ}$ caderno, p. 6.

4 - LACOMBE, América Jacobina. A queima dos arquivos da escravidão. O Jornal (Rio de Janeiro) 17 de março de 1940.

5 - RODRIgUES, José Honório. Teoria da história do Brasil. 2. a ed., rev., aum. e ilustr. São Paulo, Companhia Editora Nacional, 1957, v. 1, p. 344-350. Este capitulo sobre "Documentos perdidos" foi omitido na terceira edição da obra e incluído em $A$ pesquisa histórica no Brasil. 2. ${ }^{\text {a }}$ ed. rev. e aum. São Paulo, Companhia Editora Nacional, 1969, p. 
6 - FEDERAÇÃo INTERNACIONAL DE DOCUMENTAÇÃo. Guide de la Fédération Internationale de Documentation. La Haye, 1955, pt. I, p. 6.

7 - MALCLĖS, L.-N. Les sources du travail bibliographique. Tome I: Bibliographies générales. Genève, E. Droz; Lille, Librairie Giard, 1950, p. 268.

8 - MALCLĖS, L.-N. loc. cit.

9 - BRADFORD, S. C. Fifty years of documentation. In: - Documentation. 2.a ed. London, C. Lockwood, 1953, p. 132-143. Existe edição brasileira: Cinqüenta anos de documentação. In: - Documentação. Trad. de M. E. de Mello e Cunha. Rio de Janeiro, Fundo de Cultura, 1961, p. $180-195$.

10 - MURRA, Kathrine $O$. History of some attempts to organize bibliography internationally. In: Shera, J. H. \& Egan, M. E., ed. Bibliographic organization. Chicago, University of Chicago Press, 1951, p. 24-53.

11 - MOREIRA, Juliano, rev. cit. Apud Freire, Victor Alves da Silva. A bibliographia universal e a classificação decimal; subsidio para a participação do Brasil na organização internacional da bibliographia scientifica. São Paulo, C. Gerke, 1901,.38 p. (FID Publ. n. ${ }^{\circ}$ 54.)

12 - BEAUREPAIRE-ARAGÃO, Henrique, Noticia histórica sôbre a fundação do Instituto Oswaldo Cruz (Instituto de Manguinhos). Rio de Janeiro, 1950. 50 p. (Memórias do Instituto Oswaldo Cruz, t. 48).

13 - FREIRE, Victor Alves da Silva. op. cit. Annuário da Escola Polytechnica de S. Paulo, v. 2, p. 125-157, 1901. Artigo publicado no opúsculo -supra referenciado (ver n. ${ }^{11}$ ).

14 - SILVA, Manuel Cícero Peregrino da. Da remodelação por que passou a Biblioteca Nacional e vantagens dai resultantes. In: - Conferências, discursos, comunicações. Rio de Janeiro, Typ. do Jornal do Commercio, 1938 , p. 5-21. Reproduzido dos Anais da Biblioteca $\mathrm{Na}$ cional, v. 35 , p. 1-9, 1912. Ver também: Decreto n. 8.835 , de 11-07-1911, que aprova o Regulamento da Biblioteca Nacional. Collecção das Leis da República dos Estados Unidos do Brazil de 1911, v. 2, p. 168-188 (Rio de Janeiro, Imprensa Nacional, 1915). E ainda: Sambaquy, Lydia de Queiroz. Manuel Cícero Peregrino da Silva. IBBD Boletim Informativo (Rio de Janeiro) v. 2, n. ${ }^{\circ} 5$, p. 235-237, set./out. 1956.

15 - BIBLIOTECA NACIONAL. Boletim Bibliographico. Annos I-IV, 1918-21. Trimestral. Sairam em 1920 os números $1 / 2$ e $3 / 4$ e em 1921 apenas - número 1/2. Ver sobre o assunto: Fonseca, Edson Nery da. Bibliografia brasileira corrente: evolução e estado atual do problema. Ciência da Informação (Rio de Janeiro) v. 1, n.० 1, p. 9-14, 1972.

16 - FREYRE, Gilberto. A Biblioteca Nacional. O Cruzeiro (Rio de Janeiro) 12 de novembro de 1949, p. 10.

17 - Decreto-lei n. ${ }^{\circ}$ 2.039, de 27-02-1940. Transforma o Serviço de Publicidade do D.A.S.P. em Serviço de Documentação. D.O. 29-02-1940. É curioso constatar que, por outro dispositivo legal, foi novamente criado um Serviço de Documentação no D.A.S.P. (cf. Decreto-lei n. ${ }^{\circ}$ 4.506, de 22-07-1942. D.O. 24-07-1942.

18 - Decreto-lei n. ${ }^{\circ}$ 2.045, de 29-02-1940. Transforma, na Secretaria de Estado do Ministério da Educaçăo e Saúde, o Serviço de Publicidade em Serviço de Documentação. D.O. 02-03-1940.

19 - Decreto-lei n. ${ }^{\circ}$ 2.094, de 28-03-1940. Transforma o Serviço de Publicidade Agricola em Serviço de Informação Agrícola. D.O. 30-03-1940. 
20 - Decreto-lei n.० 4.422, de 30-06-1942. Cria o Serviço de Documentação do Departamento de Administração da Secretaria de Estado do Ministério das Relações Exteriores. D.O. 02-07-1942.

21 - Decreto-lei n. ${ }^{\circ} 5.558$, de 08-06-1943. Cria o Serviço de Documentação da Marinha. D.O. 10-06-1943.

22 - Decreto-lei n. ${ }^{\circ}$ 5.971, de 05-11-1943. Cria o Serviço de Documentação do Ministério da Justiça e Negócios Interiores. D.O. 08-11-1943.

23 - Decreto-lei n.॰ 6.431, de 17-04-1944. Cria n Serviço de Documentação do Ministério da Viação e Obras Públicas. D.O. 19-04-1944.

24 - Decreto-lei n. ${ }^{\circ}$ 6.995, de 27-10-1944. Cria o Serviço de Documentação do Ministério do Trabalho, Indústria e Comércio. D.O. 30-10-1944.

25 - Jus Documentação. Rio de Janeiro, Ministério da Justiça e Negócios Interiores, Serviço de Documentação, 1948 - Trimestral.

26 - PLACER, Xavier et alii. Catálogo das publicações do Serviço de Documentação, 1947-1965. Rio de Janeiro, Ministério da Educação e Cultura, Serviço de Documentação, 1965, 157 p.

27 - VIEIRA, José Anastácio. Informação agricola e relações públicas. Rio de Janeiro, Serviço de Informação Agrícola, 1958. 228 p. (Série documentária, n. ${ }^{\circ}$ 3).

28 - ROCHA, Augusto de Rezende. Publicidade e documentação. Revista do Serviço Público (Rio de Janeiro) v. 78, n. ${ }^{\circ} 1 / 3$, p. $3-4$, jan./mar. 1958. 0 autor deste editorial, então diretor da Revista do Serviço Público, promoveu a publicação de importantes artigos sobre documentação, de autoria de especialistas estrangeiros. Destacamos os seguintes: Coblans, Herbert. Novos métodos e técnicas de difusão de conhecimento, Trad. de Maria Amélia Pôrto Migueis, v. $78, n . \circ 1 / 3$, p. 55-84, jan./mar. 1958. Lasso de la Vega, Javier. Necessidade de aplicar um sistema orgânico à ordenação dos arquivos administrativos. Trad. de Maria Amélia Pôrto Migueis. v. 79, n. ${ }^{\circ} 1$, p. 44-60, abr. 1958. Brillouin, Léon. Ciência e informação. Trad. de Lygia Nazareth Fernandes. v. 79, n. ${ }^{\circ}$ 3, p. 254-260, jun. 1958. Gardin, Jean-Paul. Problemas da documentação. Trad. de Lygia Nazareth Fernandes. v. 80, n. ${ }^{\circ} 2$, p. 146-159 , ago. 1958. Lasso de la Vega, Javier. Bibliotecário e documentalista - uma divergência e um problema. Trad. de Lygia N. Fernandes. v. 86, n. ${ }^{\circ} 3$, p. 137-155, mar. 1960.

29 - OTLET, Paul. Documentos e documentação. Revista do Serviço Público (Rio de Janeiro) v. 1, n. ${ }^{\circ}$ 3, p. 28-31, mar. 1940. Em tradução de Francisco Martins Dias Filho, este discurso proferido no Congresso de Documentação Universal (Paris, 1937) foi publicado em separata: Documentos e documentação. Rio de Janeiro, Departamento Administrativo do Serviço Público, Serviço de Documentação, 1947. 31 p. (Publicação avulsa, n.० 254).

30 - MALCLĖS, L.-N. op. cit., p. 266.

31 - Bibliogratia Brasileira de Medicina. v. 1 -, 1937/38. Rio de Janeiro, Instituto Brasileiro de Bibliografia e Documentação, 1939.

32 - FONSECA, Edson Nery da. Informação em ciências médicas: estado atual do problema. Brasilia Médica (Brasilia) v. $2, n .0^{\circ} 1 / 2$, p. $69-75$,
mar./jun. 1968.

33 - KEFFER, Luiza. Indice bibliográfico de lepra, 1500-1943. São Paulo, Biblioteca do Departamento de Profilaxia da Lepra, 1944. 3 v. Trata-se de dépouillement de âmbito internacional e que vem sendo atualizado
por volumes suplementares.

R. Serv. Públ., Brasília, 108 (1): jan/abr. 1973 
34 - IGLÉSIAS, Dolores \& MENEGHEZZI, Maria de Lourdes, Bibliografia e indice da geologia do Brasil. 1641 - . Rio de Janeiro, Departamento Nacional da Produção Mineral, Divisão de Geologia e Mineralogia, 1943.

35 - SAMBAQUY, Lydia de Queiroz, artigo citado (ver n.0 14), p. 236.

36 - Bibliografia Econômico-Social, 1950-53. Rio de Janeiro, Fundação Getúlio Vargas, 1950-54. Diretora: Laura Maia de Figueiredo.

37 - SAMBAQUY, Lydia de Queiroz. O I.B.B.D. e os serviços que se propõe a prestar. Rio de Janeiro, Instituto Brasileiro de Bibliografia e Documentação, 1958. $23 \mathrm{p}$.

38 - COBLANS, Técnica de documentação na organização da literatura científica. Ciência e Cultura (São Paulo) v. 5 , n. 4, p. 189-193, dez. 1953.

39 - COBLANS, Herbert. Introdução ao estudo de documentação. Traduzido do original inglês por Maria Antonieta Requião Piedade. Rio de Janeiro, DASP, SD, 1957, 149 p. (Ensaios de administração, n. 8).

40 - REIS, José. Alguns problemas de documentação. Anhembi (São Paulo) v. $21, \mathrm{n} \cdot{ }^{\circ} 63$, p. $462-471$, fev. 1956.

41 - Ver artigos referenciados em nota n. ${ }^{\circ} 28$.

42 - SOCIEDADE BRASILEIRA PARA O PROGRESSO DA CIENCIA, São Paulo. Simpósio sôbre bibliografia e documentação científica, realizado com a colaboração do Conselho Nacional de Pesquisas, pelo Instituto Brasileiro de Bibliografia e Documentação... e pela Associação Paulista de Bibliotecários. São Paulo, 1956. 106 p.

43 - Documentaçăo. Jornal do Brasil (Rio de Janeiro), Suplemento Dominical (dirigido por Reynaldo Jardim), 25 de agosto; $1,15,22$ e 29 de setembro; $6,13,20$ e 27 de outubro; 3 e 17 de novembro de 1957.

44 - CONSELHO FEDERAL DE EDUCAÇÃO. Parecer n. ${ }^{\circ} 326$. In: - Curriculos dos cursos superiores: Rio de Janeiro, s.d., p. 84-86 (Separata de Documenta, n. 010 e 11). Na Universidade de Brasília, por exemplo, a matéria é desdobrada nas seguintes disciplinas: 18-238 (Documentação), 18-239 (Mecanização e Automação), 18-240 (Análise de Informações) e 18-241 (Reprografia).

45 - Ciência da Informação. v. 1 - n. $.^{\circ}-1972$ - Rio de Janeiro, Instituto Brasileiro de Bibliografia e Documentação, 1972.

46 - Bibliografia Brasileira de Documentação. v. 1 - 1811/1960. Rio de Janeiro, Instituto Brasileiro de Bibliografia e Documentação, 1960. Até dezembro de 1972 sairam 2 volumes.

47 - PAULA, Affonso Celso M. de. A documentação na Petrobrás. Revista do Serviço Público (Rio de Janeiro) v. 98, n. ${ }^{\circ} 4$, p. 5-14, out./dez. 1966.

48 - MARQUES, Silvia Augusta. Têrmos coordenados. Boletim Econômico da SUDENE (Recife) v. 5, n. ${ }^{\circ}$ 1, p. 141-162, jan./jun. 1969.

- Documentação técnico-administrativa e seu contrôle com têrmos coordenados. Belo Horizonte, VI Congresso Brasileiro de Biblioteconomia e Documentação, 1971. $2.3 \mathrm{f}$.

49 - CUNHA, Maria Emilia de Mello e \& MOURA, Maria Aparecida Gomes de. A Diretoria de Documentação e Divulgação da Secretaria Geral do Conselho Nacional de Estatística como centro de documentação especializada. A Biblioteca (Rio de Janeiro) n. ${ }^{\circ} 11$, p. 3-8, jan./mar. 1959.

50 - CENTRO BRASILEIRO DE PESQUISAS EDUCACIONAIS, Rio de Janeiro. Revista Brasileira de Estudos Pedagógicos (Rio de Janeiro) v. 24, n. ${ }^{\circ} 59$, p. $118-136$, Jul./set. 1955 ; v. 25, n. ${ }^{\circ} \in 1$, p. $145-153$, jan.Imar. 1956. Ver também Bibliografia Brasileira de Educação. v. 1- 
1953 - Rio de Janeiro, Centro Brasileiro de Pesquisas Educacionais 1954 - Trimestral.

51 - CAMPBELL, Harry C. A transmissão de informações entre bibliotecas. In: Unesco. Comunicação na era espacial. Rio de Janeiro, Fundação Getúlio Vargas, Instituto de Documentação, 1969, p. 143-155 (Ver especificamente p. 150).

52 - UNESCO. Unisist; informe del estudio sobre la posibilidad de establecer un sistema mundial de información cientifica. Montevideo, Oficina de Ciências de la Unesco para América Latina, 1971, p. 42.

53 - CÂMARA DOS DEPUTADOS. Resolução n. 20 , de 30 de novembro de 1971. Dispõe sobre a organização administrativa da Câmara dos Deputados e determina outras providências. Brasilia, Departamento de Imprensa Nacional, 1972, 137 p.

SENADO FEDERAL. Resoluçã̃o n. ${ }^{\circ} 58$, de 1972. Dispõe sobre o Regulamento Administrativo do Senado Federal. Diário do Congresso Nacional, Seção II, Ano XXVII, n.o 128, 11 de novembro de 1972, p. 4445-4489 (Serviço Gráfico do Senado Federal). 